\title{
Histoire de la France des Lumières, 1999-2005
}

\section{Daniel Roche}

\section{OpenEdition \\ Journals}

Édition électronique

URL : https://journals.openedition.org/annuaire-cdf/1078

DOI : 10.4000/annuaire-cdf. 1078

ISBN : 978-2-7226-0325-7

ISSN : 2109-9227

Éditeur

Collège de France

Édition imprimée

Date de publication : 1 avril 2013

Pagination : 804-807

ISBN : 978-2-7226-0198-7

ISSN : 0069-5580

\section{Référence électronique}

Daniel Roche, « Histoire de la France des Lumières, 1999-2005 », L'annuaire du Collège de France [En

ligne], 112 | 2013, mis en ligne le 22 novembre 2013, consulté le 22 août 2022. URL : http://

journals.openedition.org/annuaire-cdf/1078; DOI : https://doi.org/10.4000/annuaire-cdf.1078 


\section{ÉMISSIONS DE RADIO ET DE TÉLÉVISION}

France-Culture, 21 mai 2010, Vivre free, Science et conscience : «L'éternel singulier ». 31 mai 2011, Hors-antenne.

France 5, mai 2011, Sur quelle étagère?

12 mai 2011, France 5, Ce soir ou jamais.

En 2011-2012, une quarantaine d'émissions ont été enregistrées.

\section{ACTIVITÉS ANNEXES}

Membre du jury du prix littéraire de la Closerie des Lilas.

Membre du conseil d'administration de la Fondation Médéric-Alzheimer.

Membre du comité consultatif national d'éthique pour les sciences de la vie.

Membre du comité de vigilance de l'Institut Pasteur.

Membre du conseil scientifique d'Équilibre et Populations.

Membre du conseil d'administration du Fonds Non-violence XXI.

\section{PRIX ET DISTINCTIONS}

3 février 2012. Grand-Croix de l'Ordre national du mérite.

31 mai 2012. Prix Simone Veil.

29 août 2012. Grand prix du livre optimiste.

\section{Daniel ROCHE}

\section{Histoire de la France des Lumières, 1999-2005}

Mes activités de recherche ont été orientées dans trois directions principales. La première concerne l'achèvement du Dictionnaire historique de la civilisation européenne. Entamé depuis 2010, ce travail a mobilisé une équipe éditoriale d'une dizaine de collaborateurs qui a rassemblé et mis en forme un total de plus de 850 notices. Le manuscrit a été remis aux éditions Fayard et, en accord avec la direction littéraire, nous devons parachever la présentation générale (bibliographie, notes, renvois et introduction) et compléter dans la mesure du possible un certain nombre d'entrées pour lesquelles les auteurs ont soit abandonné leur travail, soit refusé leur collaboration. Vraisemblablement, l'année 2013 verra la fin de l'entreprise et peut-être la sortie de l'ouvrage pour lequel je solliciterai l'aide financière du Collège.

La seconde direction de mes travaux a été consacrée à la reprise de l'écriture du troisième - et dernier - volume de La Culture équestre de l'Occident moderne. Les trois premiers chapitres consacrés aux moyens de la connaissance culturelle, livres, 
publics, analyse spécifique du tournant de la production littéraire et savante entre le $\mathrm{XVIII}^{\mathrm{e}}$ et le début du $\mathrm{XIX}^{\mathrm{e}}$ siècle ont été achevés. Par ailleurs, j'ai avancé la documentation sur des points laissés de côté, afin de prendre en compte les renouvellements de la réflexion historiographique et sociologique depuis quelques années. Un effort particulier a été accordé à l'interrogation possible de l'art équestre, une passion, un instrument utile, une forme de métaphore de la domination politicosociale dans la perspective de la construction d'un ensemble technique, culture d'un micromilieu qui, rassemblée dans un espace sinon productif, du moins lieu d'une pédagogie spécifique, conquiert une autorité et une dignité incorporée dans ses fonctions curiales et urbaines. S'intéresser à cette transformation d'une activité pragmatique, empirique, avec ses formules et ses gestes, en art, relève de l'histoire des techniques, de la novation, de leurs transferts. En référence aux travaux de L. Hilaire-Pérez, P. Brioist, C. Verna, F. Sigault, il s'agit de contribuer à l'histoire des techniques du corps dans le rapport au vivant et la construction-expression des techniques de soi. Au total, de voir dans l'art équestre un savoir-action rassemblant finalité utilitaire, plaisir du jeu, perfectionnement esthétique par l'observation, la mise en œuvre d'expériences à travers des moyens corporels, matériels, intellectuels. L'éthos de la raison cavalière insuffle aux pratiques sa qualité particulière, ce qui permet de rejoindre l'interrogation sur la frontière établie entre les sociétés à écuyer et les sociétés cavalières, et pose l'exigence d'une meilleure connaissance de l'ethno-équitation. En d'autres termes, l'histoire de l'équitation occidentale existe, car elle a conquis le monde. Celle des sociétés cavalières doit être étendue en historicisant le modèle d'une civilisation du cheval, les usages de l'équidé de la steppe à la taïga (2008) et celui de l'Empire comanche (2012), proposés par Carole Fourret et Pekka Hänäläinen. C'est retrouver autrement la question de l'universalité des phénomènes culturels. Pour conclure sur ce point, certaines des questions soulevées ici pourront être reprises dans le domaine de la science, des sensibilités sociales, des représentations qui sont à reprendre.

Une dernière direction de travail m'a été offerte, à la demande de la Fondation 1563 per l'Arte e la Cultura de Turin, afin de réfléchir à l'orientation d'un programme de recherches sur la culture baroque dans la civilisation européenne (XVI ${ }^{\mathrm{e}}-\mathrm{XVIII}^{\mathrm{e}}$ siècles). Reprenant les apports théoriques et historiques du $\mathrm{XX}^{\mathrm{e}}$ siècle, confrontés à la vogue extraordinaire du propos saisissable sur internet, il s'agissait de rompre avec une analyse d'histoire sociale organisée par niveaux où l'art, les mentalités, les comportements baroques étaient présentés comme le résultat d'un rapport d'influence et de réciprocité entre un style, une esthétique, une société. Il fallait alors mettre en valeur la question de la temporalité de la notion qui n'a pas d'existence extérieure au corpus qui sert à la définir, tenir compte des dynamismes et des ruptures qui, à travers l'Europe, mettent en place la carte du baroque. Ils correspondent à des générations d'acteurs et à des phases de refus, de conquête et de transfert. Pour cela, l'historien est confronté au particularisme, au sentiment de continuité et de différenciation par rapport à des phénomènes de longue durée (la religion) et à l'irruption des cultures vernaculaires et orales transformés. La triple inspiration, héritée de l'historiographie (celle des interrogations des idées, des institutions qui organisent les sociétés et la conscience des hommes, celle de l'histoire des œuvres et des objets, littéraires et artistiques, qui retrouve des valeurs autonomes, mais qui hiérarchise les classements sociaux ; celle enfin des économies et des sociétés pour comprendre production et échange des œuvres) permet de qualifier autrement le rapport au social. On peut ainsi comparer les situations où se 
jouent concrètement l'invention et la consommation intellectuelles, sensibles, matérielles. Les crises, religieuses, politiques, cognitives qui construisent le cadre des défis posés aux hommes sont alors à regarder dans leur analogie et leurs tensions, la chronologie des diffusions formelles et thématiques, la géographie des séductions. Deux modèles d'analyse seraient à définir et à préciser : le premier concerne les lieux et les acteurs sociaux, villes, capitales culturelles, Cours; le second intéresse la rencontre et les valeurs de l'échange, réseaux intellectuels, religieux artistiques, théâtres, livres et éditions. Le baroque est à relire à la croisée de trois incitations, celle du comparatisme dans le temps, dans l'espace, des œuvres et des effets repérables. L'enjeu est de congédier le spectre de l'homme baroque et de retrouver les fonctionnements corrects d'une culture (J.-P. Cavaillé, Ch. Jouhaud).

\section{PubLicATIONS}

Roche D., «Les écuries royales, vitrine des chevaux du royaume », Château de Versailles, de l'Ancien Régime à nos jours, 3, 2011, 38-43.

Roche D., "Chevaux de la ville, chevaux dans la ville, le Cheval et la ville», préface dans Georgin E., (dir.), Compiègne et le cheval, Bulletin de la Société historique de Compiègne, 40, 2011, 17-24.

Roche D., «Michel Darluc, médecin, naturaliste et Républicain des sciences au XVIII ${ }^{\mathrm{e}}$ siècle », préface dans Collomp A., Un médecin des Lumières, Michel Darluc, un naturaliste provençal, Rennes, Presses universitaires, 2011, I-XII.

Roche D., «Les chevaux de Gouberville, les usages ruraux du cheval au XVI ${ }^{e}$ siècle », Provinciales, Mondot J.et Loupès Ph. (éd.), Hommage à A-M. Cocula, 2 vol., Bordeaux, 2009 [2011], 363-374.

Roche D., «Dialogue avec Christophe Charle sur l'Histoire du Livre», Histoire et civilisation du livre, Genève, VII, 2011, 371-379.

Roche D., «Aventuriers et aventures au temps de Casanova », Prévost M.L. et Thomas Ch. (éd.), Casanova, la passion de la liberté, Paris, Bibliothèque Nationale de France - Le Seuil, 2011, 164-176.

Roche D., "Échange ordinaire et consommation dynamisée, Paris au XVIII ${ }^{\mathrm{e}}$ siècle », préface de Coquery N., Tenir boutique à Paris au XVIII siècle, Luxe et demi-luxe, Paris, C.T.H.S., 2011, 11-17.

Roche D., «Les Alpes de la politique à l'intelligence », préface de Bourdon E., Le voyage et la découverte des Alpes, Histoire de la construction d'un savoir, 1492-1713, Presses universitaires de Paris Sorbonne, Paris, 2011, 9-15.

Roche D., « Sociabilité et espace public, XVII ${ }^{\mathrm{e}}-\mathrm{XVIII}$ e siècles », Libro e Lettori verso l'Italia Unita, delle fonti del Gabinetto Vieusseux, 1820-1870, Atti della Giornata di Studio, Firenze, Pallazo Strozi, 22 aprile 2010, Antologia Vieusseux, nuova serie, a, XVII, 49-50, Florence, 2011, 9-35.

\section{COMMUNICATIONS}

«L'éducation équestre», communication à la Société d'histoire et d'archéologie de Compiègne, 9 octobre 2011.

«Les historiens et la mode», séminaire, INHA, 15 novembre 2011. 
« Société et cultures, le point de vue des historiens (1960-2000) », École doctorale (Paris VII, Société et histoire moderne), 16 novembre 2011.

Conférence d'ouverture «Les conditions de l'expérience», au colloque Mobilité et circulation des savoirs, Université de Paris VII, 17 novembre 2011.

«Cheval et politique, transmission et éducation», conférence à l'université de Genève, 22 novembre 2011.

«Équitation et société », Centre d'histoire de la Renaissance (P. Brioist), université de Tours, 11 février 2012.

«Le Baroque, culture et réflexion sur l'âge baroque, $\mathrm{XVII}$-XVIII ${ }^{\mathrm{e}}$ siècles », conférence à l'Istituto San Paulo - 1563, 7 mars 2012.

« Histoire des idées, histoire culturelle, histoire des sociabilités », intervention au séminaire de doctorat, M. Roggero, université de Turin, 8 mars 2012.

«L'équitation et la politique (XVI $-\mathrm{XIX}^{\mathrm{e}}$ siècles) », communication à la Société des lettres, sciences et arts de Rodez, 5 mai 2012.

\section{FONCTIONS ADMINISTRATIVES}

Directeur de la Revue d'histoire moderne et contemporaine.

Membre du conseil scientifique de l'École des Chartes.

Membre du conseil scientifique de l'université de Paris I.

\section{DISTINCTION}

Élu membre académicien correspondant étranger de la classe des sciences morales, section des sciences philosophiques, pédagogiques et morales de l'Institut de Bologne (juillet 2011).

\section{Jean-Pierre SERRE, membre de l'Institut (Académie des sciences)}

\section{Algèbre et géométrie, 1956-1994}

\section{Publications}

Serre J.-P., Le groupe de Cremona et ses sous-groupes finis, séminaire Bourbaki 2008/2009, exposé no 1000, Astérisque, 332, 2010, 75-100.

Serre J.-P., lettre à N. Karoubi, reproduite en appendice dans : Karoubi N., Clifford modules and invariants of quadratic forms, Journal of K-theory, 9, 2012, 1-44.

Serre J.-P., Lectures on $N \times(p)$, AK Peters, CRC Press, Taylor and Francis, New York, 2012, $174 \mathrm{p}$.

Serre J.-P. et Nicolas J.-L., Formes modulaires modulo 2 : l'ordre de nilpotence des opérateurs de Hecke, C.R.A.S., 350, 2012, 343-348. 